\title{
Noninvasive Monitoring during Interhospital Transport of Newborn Infants
}

\author{
Georg M. Schmölzer, ${ }^{1,2,3}$ Megan O'Reilly, ${ }^{1}$ and Po-Yin Cheung ${ }^{1,2}$ \\ ${ }^{1}$ Department of Pediatrics, University of Alberta, Edmonton, AB, Canada 11405-87 \\ ${ }^{2}$ Neonatal Research Unit, Royal Alexandra Hospital, 10240 Kingsway Avenue NW, Edmonton, AB, Canada T5H 3V9 \\ ${ }^{3}$ Division of Neonatology, Department of Pediatrics, Medical University of Graz, 8010 Graz, Austria \\ Correspondence should be addressed to Georg M. Schmölzer; georg.schmoelzer@me.com
}

Received 24 September 2012; Revised 4 January 2013; Accepted 8 January 2013

Academic Editor: Marcus J. Schultz

Copyright (C) 2013 Georg M. Schmölzer et al. This is an open access article distributed under the Creative Commons Attribution License, which permits unrestricted use, distribution, and reproduction in any medium, provided the original work is properly cited.

\begin{abstract}
The main indications for interhospital neonatal transports are radiographic studies (e.g., magnet resonance imaging) and surgical interventions. Specialized neonatal transport teams need to be skilled in patient care, communication, and equipment management and extensively trained in resuscitation, stabilization, and transport of critically ill infants. However, there is increasing evidence that clinical assessment of heart rate, color, or chest wall movements is imprecise and can be misleading even in experienced hands. The aim of the paper was to review the current evidence on clinical monitoring equipment during interhospital neonatal transport.
\end{abstract}

\section{Introduction}

The main indications for interhospital neonatal transports are radiographic studies (e.g., magnet resonance imaging) and surgical interventions. Specialized neonatal transport teams need to be skilled in patient care, communication, and equipment management and extensively trained in resuscitation, stabilization, and transport of critically ill infants [1]. Clinical monitoring equipment routinely used in the neonatal intensive care unit (NICU) may not function optimally under transport conditions [2]. Both the critically ill neonate and the neonatal transport team are exposed to mechanical stressors (e.g., shock, vibration, and noise) making clinical assessment during transport almost impossible [1, 3-9]. However, most of the equipment routinely used in the NICU to support clinical management decisions has not been evaluated in the transport environment. The aim of the paper was to review the current evidence on clinical monitoring equipment during interhospital neonatal transport.

\section{Search Strategies}

The aim of this paper is to review the available literature about monitoring during interhospital neonatal transport.
We reviewed books, resuscitation manuals, and articles from 1950 to the present with the search terms "infant," "newborn," "neonatal transport," "pulse oximetry," "heart rate," "respiratory function tests," "carbon dioxide," "temperature," "blood pressure monitoring" and "transport scores." The full search strategy for PubMed is detailed in the Appendix.

\section{Pulse Oximetry and Heart Rate}

Neonatal transports carried out overnight make the assessment of an infant's color challenging. In addition, incubators are covered to decrease environmental impact, which blocks light inside the incubator making color assessment challenging. Furthermore, judging an infants color to determine oxygen saturation is imprecise [10]. During neonatal transport, vibration can cause intermittent failure or signal artifacts $[6,11,12]$. Short et al. tested seven different pulse oximeters during helicopter flights, and the majority of pulse oximeters demonstrated minimal signal artifacts [6].

HR is the most important clinical indicator of adequate breathing and respiratory support $[13,14]$. International resuscitation guidelines recommend to assess an infant's HR during neonatal resuscitation using a stethoscope [14]. However, an observational delivery room study showed that 
auscultation is inaccurate and underestimates HR compared to HR measurements using electrocardiogram $[15,16]$. Kamlin et al. demonstrated that HR displayed by pulse oximetry is as accurate as HR obtained by a 3-lead electrocardiogram, including those newborns receiving advanced resuscitation [17]. Hence, pulse oximetry can be used to monitor an infant's HR during neonatal transport. In addition, the HR is displayed continuously allowing the team to continue any neonatal transport without stopping to listen to the HR.

In summary, pulse oximetry should be the standard of care for managing infants during neonatal transport, enabling immediate and dynamic assessment of oxygenation and heart rate.

\section{Noninvasive Blood Pressure Monitoring}

Norm values of BP in newborn infants are derived from a reference population with regard to gestational age, birth weight, and postnatal age [18-20]. Overall, different definitions are used to diagnose neonatal hypotension: (i) BP $<10$ th percentile of normative blood pressure values, (ii) mean arterial blood pressure equals gestational age in whole weeks and no other signs of hypoperfusion (e.g., high serum lactate concentration or oliguria) exist. This definition can only be used within the first 5 days after birth as mean arterial blood pressure increases up to $10 \mathrm{mmHg}$ during this time, and (iii) mean arterial blood pressure $<30 \mathrm{mmHg}$, which is based on the assumption that cerebral blood flow becomes pressure dependent at a mean arterial blood pressure around $30 \mathrm{mmHg}[18,19]$. The goal of blood pressure (BP) monitoring is to optimize cardiac output, which is generally relied on by clinical assessment, $\mathrm{HR}$, and $\mathrm{BP}$ monitoring. Therefore, adequate BP does not always indicate adequate cardiac output. Continuous arterial BP monitoring using an indwelling catheter is considered the "gold standard" of BP measurement in the critically ill neonate $[18,19]$. Although $\mathrm{BP}$ is also frequently noninvasively measured, it is less accurate (especially in severe hypotension) and not continuous. Most importantly noninvasive BP measurements are not continuous, inaccurate (overestimation of hypotension and underestimation of hypertension), and unable to provide reliable mean or diastolic arterial BP. However, they can be used for trends in BP changes $[18,19]$. Noninvasive BP measurements should be available for all transported newborns, however automated non-invasive BP devices can be affected by vibration and motion. In addition, various cuff sizes are needed as a too small cuff overestimates blood pressure.

\section{Respiratory Function Monitor (RFM)}

During neonatal resuscitation, mask ventilation should be guided by observing chest rise $[14,21]$. However, recent observational studies in the delivery room have demonstrated that observation of chest rise movements to assess positive pressure ventilation is imprecise $[22,23]$. A similar thing can be said during neonatal transport, where assessment of chest rise to assess ventilation is limited. In comparison, a respiratory function monitor (RFM) provides objective measurements of continuously measured respiratory parameters [1, 24, 25].
In comparison, guidance of mechanically ventilated newborn infants by displayed respiratory function is a standard of care in the NICU [26]. In addition, tidal volume monitoring has recently been advocated for neonatal resuscitation and neonatal simulation [23-25, 27-29]. However, this technique has not been implemented during neonatal transport. During neonatal transport, mechanical ventilation is indirectly assessed using $\mathrm{HR}, \mathrm{SpO}_{2}$, chest rise, end-tidal $\mathrm{CO}_{2}\left(\mathrm{ETCO}_{2}\right)$ or transcutaneous $\mathrm{CO}_{2}-\left(\mathrm{TCO}_{2}\right)$, and $\mathrm{O}_{2}-$ tension [30-33]. Observational studies in the delivery room have demonstrated that chest rise is a poor proxy for tidal volume delivery regardless of the level of experience [22, 23]. Tracy et al. reported that $25 \%$ of preterm infants receiving positive pressure ventilation (PPV) while transported from the delivery room to the NICU had hypocapnia on arrival $[34,35]$. They showed that by 20 minutes after birth, $20 \%$ of infants had a $\mathrm{PaCO}_{2}$ below $25 \mathrm{~mm} \mathrm{Hg}$-a known risk factor for brain injury $[35,36]$. Lilley et al. reported similar results. Infants were more likely to be overventilated when clinical assessment was used to guide PPV during neonatal transport [37]. In comparison, when an RFM was used, target $\mathrm{TCO}_{2}$ tension was achieved within 15 minutes after PPV was started [37]. However, the study design and low numbers of included infants did not allow the results to be directly attributed to the use of the RFM.

A respiratory function monitor (RFM) continuously displays graphical waveforms and numerical values of peak inflation pressure (PIP), positive end-expiratory pressure (PEEP), tidal volume $\left(V_{T}\right)$, leak around an endotracheal tube (ETT), minute ventilation, respiratory rate, and inspiration and expiration times (Figure 1) [1, 24, 25]. To measure respiratory function, a flow sensor is placed between the ventilator and an ETT; $V_{T}$ is automatically calculated by integrating the flow signal, and leak around the ETT is displayed as a percentage of the inspired $V_{T}$ [38]. Airway pressures (e.g., PIP and PEEP) are directly measured from the circuit. We believe that during neonatal transport, an RFM can be used to (i) identify leak around an ETT (Figure 2) [24, 39, 40], accidental extubation (Figure 3) [24, 39-41], airway obstruction (Figure 4) $[24,42]$, adequate $V_{T}$ delivery (Figure 5) [22, 23, 27], and observing spontaneous breathing during mechanical ventilation (Figure 6) [24, 43-45].

5.1. Endotracheal Tube Size. An RFM can show the percentage of leak around the ETT. With an appropriate sized ETT, any leak will be small. However, if a too narrow ETT is inserted, a large leak of the inflating volume around the ETT will be displayed at any RFM (Figure 2). This means that insufficient gas enters the lung, which may result in unsatisfactory mechanical ventilation. The use of an RFM enables the transport team to observe the ETT leak continuously during every breath cycle and assess if the ETT size should be changed $[24,37]$.

5.2. Accidental Extubation. During neonatal transport, an ETT can easily become dislodged. This can be seen immediately on the flow and volume signals as there is little or no expiratory flow and volume (Figure 3) [24]. 


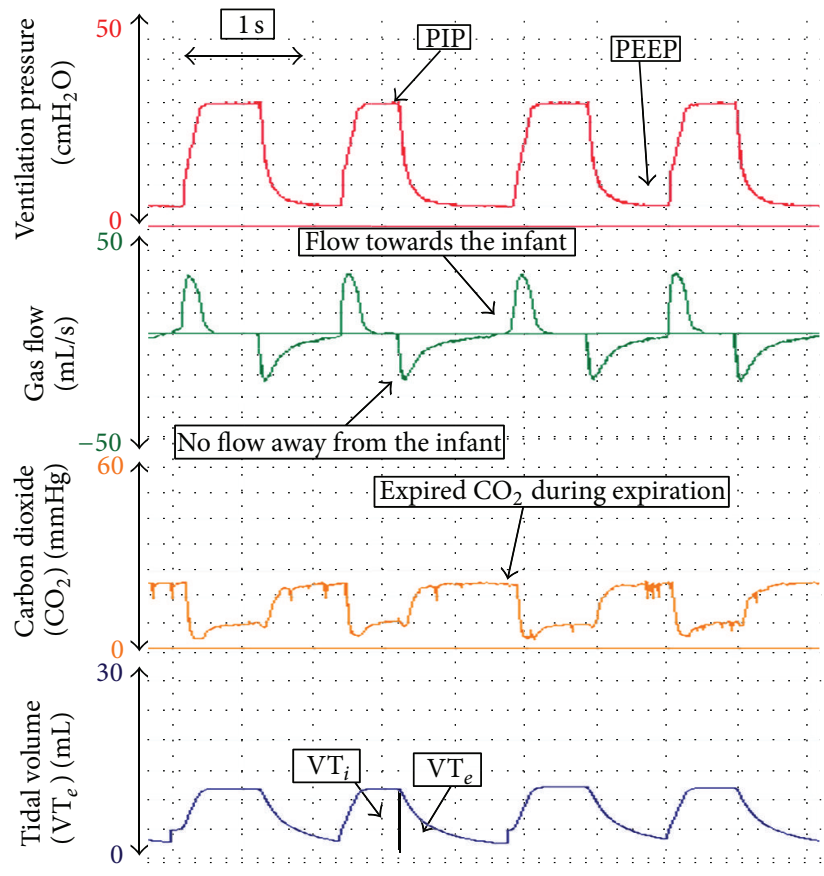

FIGURE 1: During positive pressure ventilation (PPV), the airway pressures rise to set PIP. At the end of inspiration, PIP decreases to baseline (PEEP). The area underneath the gas flow waves during inflation and expiration is similar, which is reflected in the $V_{T}$ wave returning to the baseline after expiration. No leak is displayed.

5.3. Airway Obstruction. If there is little or no increase in a low $V_{T}$ wave in response to an increase in PIP, then airway obstruction should be considered [24]. Airway obstruction has been reported during mask ventilation $[42,46]$, after surfactant administration [47, 48], and blockage due to blood or secretion. Figure 4 demonstrates adequate PPV via an ETT. Suddenly, the ETT becomes obstructed, which is indicated by almost no gas flow and no $V_{T}$ wave.

5.4. Tidal Volume Delivery. The purpose of applying a PIP during PPV is to inflate the lungs with an appropriate tidal $V_{T}$ and thereby facilitate gas exchange [24]. When a fixed pressure is used, the delivered $V_{T}$ will be dependent on the size of the infant, compliance of the lungs and chest wall, and resistance of the airways $[24,29,49,50]$. Too high $V_{T}$ delivery can cause lung injury by over inflation and hypocapnia, and too small $V_{T}$ will result in inadequate gas exchange $[15,24,29$, $30,35,51-55]$. The current evidence suggests that $V_{T}$ should be within the range of 4 to $8 \mathrm{~mL} / \mathrm{kg}[26,29,51]$. Using an RFM during neonatal transport enables the transport team to adjust the set PIP to ensure adequate $V_{T}$ is delivered (Figure 5). The optimum PIP will vary between infants and in the same infant over time depending of the cause of lung injury (e.g., congenital diaphragmatic hernia, lung hypoplasia, meconium aspiration, or bronchopulmonary dysplasia).

5.5. Observing Spontaneous Breathing. During mechanical ventilation, an RFM attached to an ETT can be used to display the spontaneous $V_{T}$ and interactions between spontaneous



FIgure 2: During PPV, the area underneath inspiratory gas flow is larger compared to expiratory gas flow. This is reflected in the display of a large amount of leak around the ETT.

breaths and inflations made by the ventilator (Figure 6) $[24,45,56]$. This can assist the neonatal team to determine if a ventilated newly born infant is apnoeic, or breathing synchronously or asynchronously with the manual inflations [24]. An RFM may show the infant "fighting the ventilator" and breathing completely out of phase with the mechanical inflations (e.g., infant inspires during mechanical expiration and expires during inflations), which is inefficient and potentially traumatic $[24,56,57]$.

\section{Carbon Dioxide Monitoring}

Continuous noninvasive $\mathrm{CO}_{2}$ monitoring (e.g., $\mathrm{ETCO}_{2}$ or $\mathrm{TCO}_{2}$ ) has become an important bedside tool during neonatal transport $[31,33]$. ETCO $_{2}$ can be measured using either main-, side- or microstream technology [31, 33, 58]. Clinical applications for $\mathrm{CO}_{2}$ monitoring include (i) confirmation of correct tube placement and (ii) guidance of mechanical ventilation $[31,33,39,40]$.

6.1. Confirmation of Correct Tube Placement. Bhende et al. reported that $\mathrm{ETCO}_{2}$ can be used to assess correct ETT position during neonatal transport [33]. However, recent delivery room studies have demonstrated that $\mathrm{ETCO}_{2}$ monitoring 


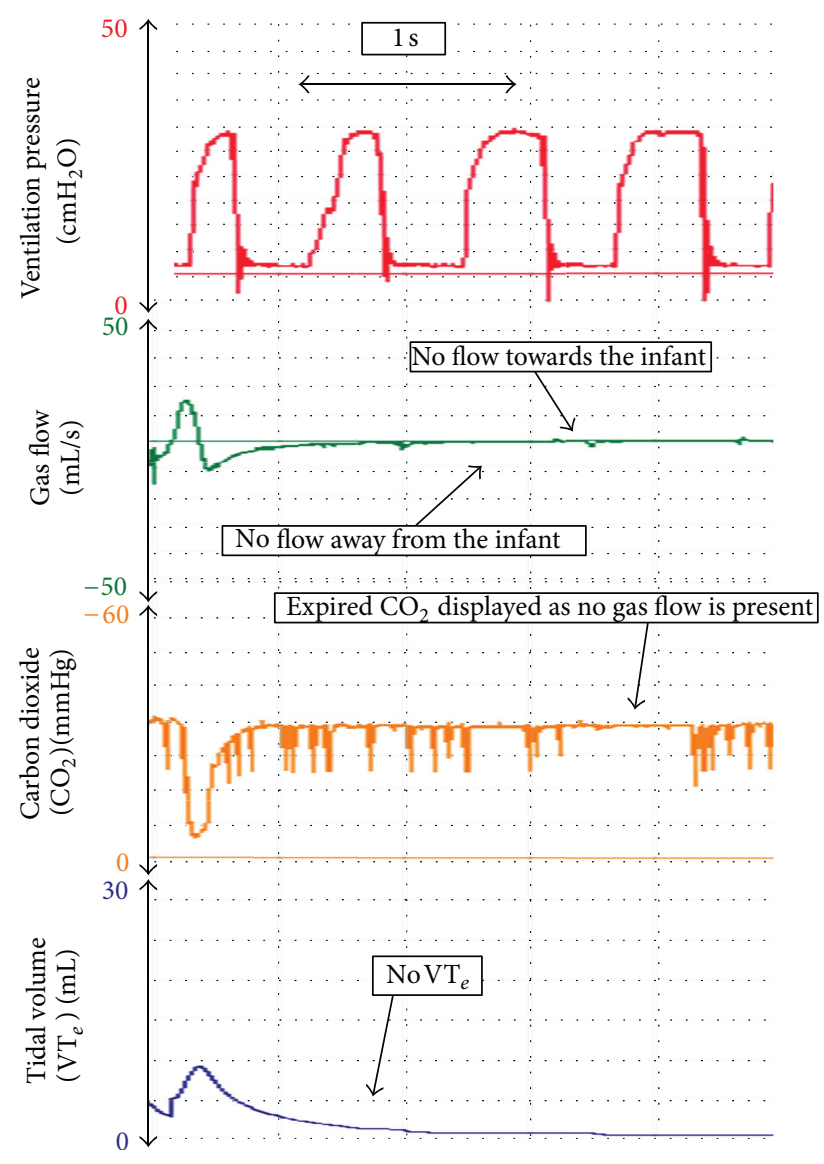

FIGURE 3: During PPV, the ETT suddenly becomes obstructed, which can be identified by gas flow and $V_{T}$ cessation. Airway pressures are continuously delivered.

failed to correctly identify ETT placement in up to one third of the cases $[39,59]$.

6.2. Guidance of Mechanical Ventilation. The gold standard for assessing the adequacy of mechanical ventilation is arterial blood gas analysis [60]. However, noninvasive $\mathrm{CO}_{2}$ monitoring has become an important bedside tool during neonatal transport [31, 33, 60, 61]. Several studies compared arterial $\mathrm{CO}_{2}$ with $\mathrm{ETCO}_{2}$ or $\mathrm{TCO}_{2}$ values $[31,33,60,61]$. Tingay et al. compared $\mathrm{ETCO}_{2}$, $\mathrm{TCO}_{2}$, and arterial $\mathrm{CO}_{2}$ during neonatal transport [31]. They found no correlation between $\mathrm{ETCO}_{2}$ and arterial $\mathrm{CO}_{2}$ measurements [31], suggesting that $\mathrm{TCO}_{2}$ should currently be used during neonatal transport. Tobias summarized the available literature of $\mathrm{TCO}_{2}$ in infants and children [62]. When compared to $\mathrm{ETCO}_{2}, \mathrm{TCO}_{2}$ is as accurate in patients with normal respiratory function. In addition, it was more accurate in patients with congenital heart disease and right-to-left shunting [62]. However, $\mathrm{ETCO}_{2}$-monitoring remains the standard of care to demonstrate the correct ETT placement or ETT disconnection. Overall, there are several limitation to each technique [31,33, 60,61]. Although arterial blood gas analysis is the gold standard, the monitoring is not feasible particularly in the prehospital setting because of the lack of specialized equipment and expertise required

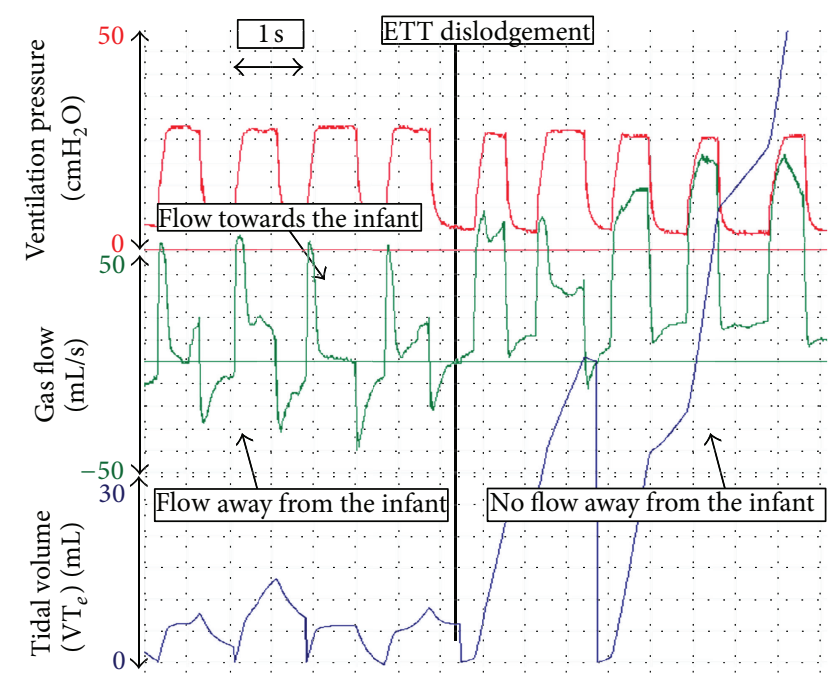

FIGURE 4: During PPV, the ETT suddenly becomes dislodged.

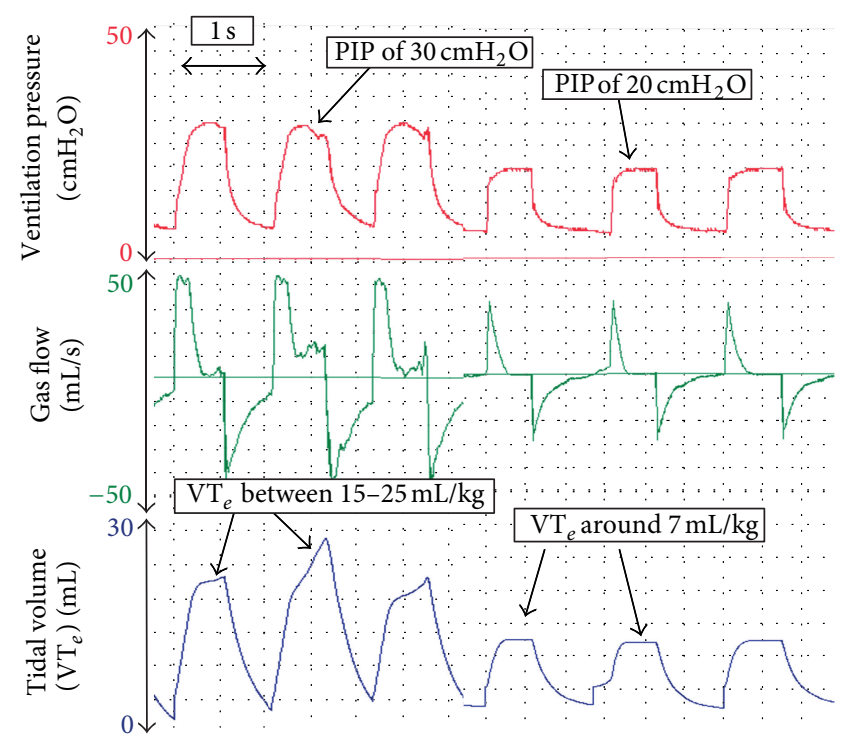

FIGURE 5: During PPV, the delivered $V_{T}$ is between 21 and $30 \mathrm{~mL} / \mathrm{kg}$. Once the PIP is decreased from $30 \mathrm{~cm} \mathrm{H}_{2} \mathrm{O}$ to $20 \mathrm{~cm} \mathrm{H}_{2} \mathrm{O}$, the displayed $V_{T}$ decreases to around $9 \mathrm{~mL} / \mathrm{kg}$.

for placement and monitoring [2]. Major concerns while using $\mathrm{TCO}_{2}$ include (i) vasodilatation of the capillary bed beneath the $\mathrm{TCO}_{2}$ probe, which might cause $\mathrm{TCO}_{2}$ value alterations, (ii) heating of the $\mathrm{TCO}_{2}$ probe to $43^{\circ} \mathrm{C}$ can cause burn injuries and increases tissue metabolic rate by $4-5 \%$ for every ${ }^{\circ} \mathrm{C}$, (iii) improper calibration, trapped air bubbles, and damaged membranes are possible and may be difficult to detect, (iv) hyperxemia $\left(\mathrm{PaO}_{2}>100\right.$ torr), (v) shock or acidosis, (vi) or improper electrode placement might increase the discrepancy between arterial $\mathrm{CO}_{2}$ and $\mathrm{TCO}_{2}$ values $[1$, $60,62,63]$. In comparison, birth weight, site of $\mathrm{TCO}_{2}$ probe, mean blood pressure and airway pressure do not affect $\mathrm{TCO}_{2}$ measurement $[1,60,62,63]$. Although $\mathrm{ETCO}_{2}$ and $\mathrm{TCO}_{2}$ are promising the current available methods should only be 


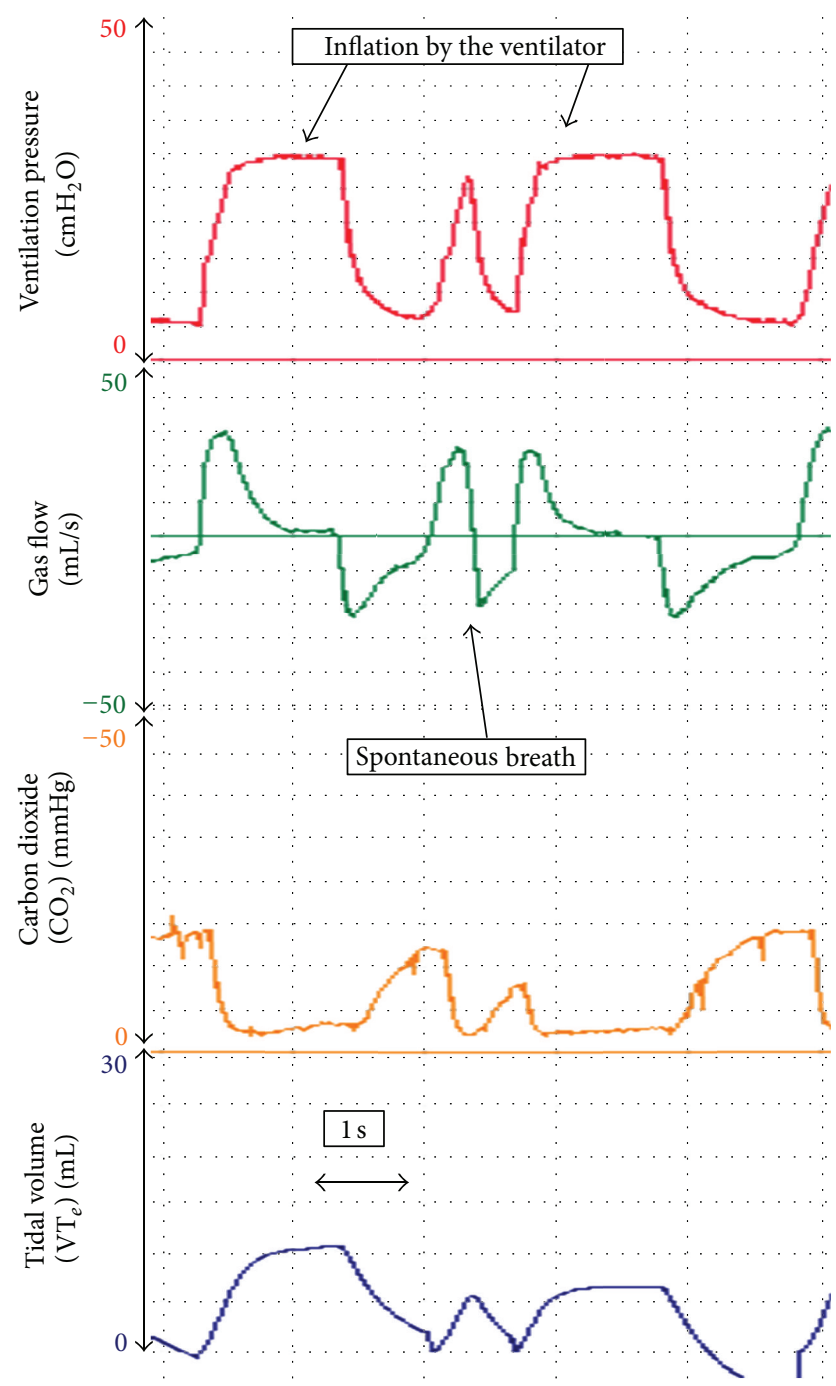

FIGURE 6: During manual inflations the infant is taking a spontaneous breath.

used to complete arterial $\mathrm{CO}_{2}$ monitoring during neonatal transport.

\section{Temperature}

Maintaining the thermal environment for newborn infants and avoidance of cold stress is important for short- and longterm outcomes [64]. Rates of hypothermia $(<36 \%)$ decreased over the last decades during neonatal transport $[3,5,65]$. However, one third of the infants $\leq 1000 \mathrm{~g}$ had hypothermia at arrival of the transport team, and remained hypothermic despite active warming [65]. In comparison, a significant increase in hyperthermia from $12 \%$ in $1977-79$ to $24 \%$ in 1995 96 has been observed for all infants except for infants $\leq 1000 \mathrm{~g}$ [65].

Recently whole-body cooling for hypoxic ischemic encephalopathy has been introduced during neonatal transport. Whole-body cooling can be achieved by using either passive (naturally cooling with no external intervention) or active (e.g., cold gel-packs) cooling [66-70]. Both methods have the potential for both over- and undercooling particularly without appropriate monitoring [67-70].

The optimal method to monitor body temperature during whole-body cooling remains controversial. Esophageal temperature monitoring has been reported to be more accurate compared to measurements obtained from tympanic, rectal, axillary, or the bladder [70]. In addition, skin probes rely on skin perfusion and are unreliable during whole-body cooling [70]. Currently, rectal probes should be used to continuously monitor body temperature during therapeutic hypothermia.

\section{Neonatal Scores}

Different neonatal scores are used to assess newborn infants [71-77]. The transport risk index of physiologic stability (TRIPS) (temperature, BP, respiratory distress/pulse oximetry, and response to noxious stimuli) assesses an infant before and after transport, and change is detected by comparing pre- and posttransport scores [71, 74]. A higher total TRIPS score indicates more severely ill newborn, and a higher posttransport score has been associated with increased neonatal mortality and intraventricular hemorrhage. The score for neonatal acute physiology II (SNAP-II) (mean BP, temperature, $\mathrm{PO}_{2} / \mathrm{FiO}_{2}$ ratio, serum $\mathrm{pH}$, seizures, and urine output) and SNAP-perinatal extension-II (SNAPPE-II) (additionally to SNAP includes birth weight, 5-minute Apgar score, and small for gestational age) are illness severity and mortality risk scores for newborns in the NICU [71-77]. SNAP-II has been validated as a measure of newborn illness severity and SNAPPE-II as a measure of mortality risk however; both scores were not originally designed to assess interhospital transport [76]. Two studies compared the scores for infants receiving neonatal transport. Lee et al. did not find a significant difference between TRIPS and SNAP-II in their ability to predict mortality and severe intraventricular hemorrhage [74]. In comparison, Lucas de Silva et al. reported that TRIPS scores at admission were able to predict one week mortality in preterm infants $<32$-weeks gestation [77].

In summary, TRIPS score calculated at admission is predictive of early neonatal mortality in infants with $<32$ week gestation. TRIPS might be a useful triage tool if applied at the time of first contact with a transport service.

\section{Conclusion}

The information presented in this paper is from applicable animal and clinical studies during neonatal transport, the NICU, and during delivery room resuscitation. Unfortunately, there is a lack of data and randomized studies during neonatal transport, which are urgently needed. However, it is extremely difficult to undertake good detailed randomized studies during emergency neonatal transports. We leave it to the reader to interpret the results of the presented studies. However, any neonatal transport team requires skills in patient care and equipment management. In addition, advanced training in neonatal resuscitation, stabilization, and transport of these infants are pinnacle. 


\section{Appendix}

\section{Search Strategy for PubMed}

(Last search 01/01/2013): limits activated (human)

\#1 MeSH Term “Infant” (result: 847,904)

\#2 MeSH Term “Newborn” (result: 470,261)

\#3 Keyword "Neonatal transport" (result: 1,873)

\#4 ((\#1) AND \#2) AND \#3 (result: 1,247)

\#5 MeSH Term "Pulse Oximetry” (result: 11,191)

\#6 MeSH Term “Heart Rate” (result: 171,586)

\#7 MeSH Term "Respiratory Function" Tests (result: 160,697)

\#8 MeSH Term “Carbon Dioxide” (result: 39,322)

\#9 MeSH Term “Temperature” (result: 149,958)

\#10 MeSH Term "Blood Pressure monitoring" (result: 28,404)

\#11 Keyword "Transport Scores"

\#12 (\#4) AND \#5 (result: 22)

\#13 (\#4) AND \#6 (result: 29)

\#14 (\#4) AND \#7 (result: 176)

\#15 (\#4) AND \#8 (result: 46)

\#16 (\#4) AND \#9 (result: 79)

\#17 (\#4) AND \#10 (result: 13)

\#18 (\#4) AND \#11 (result: 35)

\section{Abbreviations}

NICU: Neonatal intensive care unit

$\mathrm{SpO}_{2}: \quad$ Oxygen saturation

HR: Heart rate

BP: $\quad$ Blood pressure

RFM: Respiratory function monitor

ETT: $\quad$ Endotracheal tube

PIP: $\quad$ Peak inflation pressure

PEEP: $\quad$ Positive end-expiratory pressure

$V_{T}: \quad$ Tidal volume

$\mathrm{CO}_{2}$ : $\quad$ Carbon dioxide

$\mathrm{ETCO}_{2}$ : $\quad$ End tidal carbon dioxide

$\mathrm{TCO}_{2}$ : $\quad$ Transcutaneous carbon dioxide

PPV: $\quad$ Positive pressure ventilation

TRIPS: $\quad$ Transport risk index of physiologic stability

SNAP-II: $\quad$ Score for neonatal acute physiology II

SNAPPE-II: SNAP-perinatal extension-II.

\section{Conflict of Interests}

The authors declare that they have no conflict of interests.

\section{References}

[1] M. O’Reilly and G. M. Schmölzer, "Monitoring during Neonatal transport," Emergency Medicine, vol. 1, 2012.
[2] M. H. Stroud, P. Prodhan, M. Moss, R. Fiser, S. Schexnayder, and K. Anand, "Enhanced monitoring improves pediatric transport outcomes: a randomized controlled trial," Pediatrics, vol. 127, no. 1, pp. 42-48, 2011.

[3] A. Meberg, "Neonatal transports-risks and opportunities," Open Journal of Pediatrics, vol. 1, pp. 45-50, 2011.

[4] S. T. Kempley, N. Ratnavel, and T. Fellows, "Vehicles and equipment for land-based neonatal transport," Early Human Development, vol. 85, no. 8, pp. 491-495, 2009.

[5] L. Jackson and C. H. Skeoch, "Setting up a neonatal transport service: air transport," Early Human Development, vol. 85, no. 8, pp. 477-481, 2009.

[6] L. Short, R. B. Hecker, R. E. Middaugh, and E. J. Menk, "A comparison of pulse oximeters during helicopter flight," Journal of Emergency Medicine, vol. 7, no. 6, pp. 639-643, 1989.

[7] S. E. Sittig, J. C. Nesbitt, D. A. Krageschmidt, S. C. Sobczak, and R. V. Johnson, "Noise levels in a neonatal transport incubator in medically configured aircraft," International Journal of Pediatric Otorhinolaryngology, vol. 75, no. 1, pp. 74-76, 2011.

[8] R. C. Hunt, D. M. Bryan, V. S. Brinkley, T. W. Whitley, and N. H. Benson, "Inability to assess breath sounds during air medical transport by helicopter," Journal of the American Medical Association, vol. 265, no. 15, pp. 1982-1984, 1991.

[9] J. C. Bouchut, E. van Lancker, V. Chritin, and P. Y. Gueugniaud, "Physical stressors during neonatal transport: helicopter compared with ground ambulance," Air Medical Journal, vol. 30, no. 3, pp. 134-139, 2011.

[10] C. P. F. O’Donnell, C. O. F. Kamlin, P. G. Davis et al., "Clinical assessment of infant colour at delivery," Archives of Disease in Childhood-Fetal and Neonatal Edition, vol. 92, pp. F465-F467, 2007.

[11] J. A. Langton and C. D. Hanning, "Effect of motion artefact on pulse oximeters: evaluation of four instruments and finger probes," British Journal of Anaesthesia, vol. 65, no. 4, pp. 564570, 1990.

[12] R. Sahni, A. Gupta, K. Ohira-Kist, and T. S. Rosen, "Motion resistant pulse oximetry in neonates," Archives of Disease in Childhood-Fetal and Neonatal Edition, vol. 88, no. 6, pp. F505F508, 2003.

[13] C. H. Yam, J. A. Dawson, G. M. Schmölzer et al., "Heart rate changes during resuscitation of newly born infants," Archives of Disease in Childhood-Fetal and Neonatal Edition, vol. 96, pp. F102-F107, 2011.

[14] J. Kattwinkel, J. M. Perlman, K. Aziz et al., "Part 15: neonatal resuscitation: 2010 American Heart Association Guidelines for Cardiopulmonary Resuscitation and Emergency Cardiovascular Care," Circulation, vol. 122, no. 3, pp. S909-S919, 2010.

[15] L. J. Björklund, J. Ingimarsson, T. Curstedt et al., "Manual ventilation with a few large breaths at birth compromises the therapeutic effect of subsequent surfactant replacement in immature lambs," Pediatric Research, vol. 42, no. 3, pp. 348-355, 1997.

[16] C. O. F. Kamlin, C. P. F. O’Donnell, N. J. Everest, P. G. Davis, and C. J. Morley, "Accuracy of clinical assessment of infant heart rate in the delivery room," Resuscitation, vol. 71, no. 3, pp. 319-321, 2006.

[17] C. O. F. Kamlin, J. A. Dawson, C. P. F. O’Donnell et al., "Accuracy of pulse oximetry measurement of heart rate of newborn infants in the delivery room," The Journal of Pediatrics, vol. 152, no. 6, pp. 756-760, 2008. 
[18] W. P. de Boode, "Clinical monitoring of systemic hemodynamics in critically ill newborns," Early Human Development, vol. 86, no. 3, pp. 137-141, 2010.

[19] S. Soleymani, M. Borzage, and I. Seri, "Hemodynamic monitoring in neonates: advances and challenges," Journal of Perinatology, vol. 30, no. 1, pp. S38-S45, 2010.

[20] S. Noori, A. Wlodaver, V. Gottipati et al., "Transitional changes in cardiac and cerebral hemodynamics in term neonates at birth," The Journal of Pediatrics, vol. 160, no. 6, pp. 943-948, 2012.

[21] N. H. Hillman, S. G. Kallapur, J. J. Pillow et al., "Airway injury from initiating ventilation in preterm sheep," Pediatric Research, vol. 67, no. 1, pp. 60-65, 2010.

[22] D. A. Poulton, G. M. Schmölzer, C. J. Morley, and P. G. Davis, "Assessment of chest rise during mask ventilation of preterm infants in the delivery room," Resuscitation, vol. 82, no. 2, pp. 175-179, 2011.

[23] G. M. Schmölzer, C. O. F. Kamlin, C. P. F. O’Donnell, J. A. Dawson, C. J. Morley, and P. G. Davis, "Assessment of tidal volume and gas leak during mask ventilation of preterm infants in the delivery room," Archives of Disease in Childhood-Fetal and Neonatal Edition, vol. 95, pp. F393-F397, 2010.

[24] G. M. Schmölzer, C. O. F. Kamlin, J. A. Dawson et al., "Respiratory monitoring of neonatal resuscitation," Archives of Disease in Childhood_Fetal and Neonatal Edition, vol. 95, pp. F295-F303, 2010.

[25] G. M. Schmölzer and C. C. Roehr, "Use of respiratory function monitors during simulated neonatal resuscitation," Klinische Pädiatrie, vol. 223, pp. 261-266, 2011.

[26] C. Klingenberg, K. I. Wheeler, P. G. Davis et al., "A practical guide to neonatal volume guarantee ventilation," Journal of Perinatology, vol. 31, pp. 575-585, 2011.

[27] G. M. Schmölzer, C. J. Morley, C. Wong et al., "Respiratory function monitor guidance of mask ventilation in the delivery room: a feasibility study," The Journal of Pediatrics, vol. 160, pp. 377.e2-381.e2, 2012.

[28] G. M. Schmölzer, C. J. Morley, and P. G. Davis, "Respiratory function monitoring to reduce mortality and morbidity in newborn infants receiving resuscitation," Cochrane Database of Systematic Reviews, vol. 9, Article ID CD008437, 2010.

[29] G. M. Schmölzer, A. B. te Pas, P. G. Davis et al., "Reducing lung injury during neonatal resuscitation of preterm infants," The Journal of Pediatrics, vol. 153, pp. 741-745, 2008.

[30] G. R. Polglase, N. H. Hillman, J. J. Pillow et al., "Positive endexpiratory pressure and tidal volume during initial ventilation of preterm lambs," Pediatric Research, vol. 64, no. 5, pp. 517-522, 2008.

[31] D. G. Tingay, M. J. Stewart, and C. J. Morley, "Monitoring of end tidal carbon dioxide and transcutaneous carbon dioxide during neonatal transport," Archives of Disease in Childhood-Fetal and Neonatal Edition, vol. 90, no. 6, pp. F523-F526, 2005.

[32] S. L. Barnes, R. Branson, L. A. Gallo, G. Beck, and J. A. Johannigman, "En-route care in the air: snapshot of mechanical ventilation at 37,000 feet," The Journal of Trauma, vol. 64, no. 2, pp. S129-S134, 2008.

[33] M. S. Bhende, V. A. Karr, D. C. Wiltsie, and R. A. Orr, "Evaluation of a portable infrared end-tidal carbon dioxide monitor during pediatric interhospital transport," Pediatrics, vol. 95, no. 6, pp. 875-878, 1995.

[34] A. B. te Pas, M. Siew, M. J. Wallace et al., "Effect of sustained inflation length on establishing functional residual capacity at birth in ventilated premature rabbits," Pediatric Research, vol. 66, no. 3, pp. 295-300, 2009.

[35] M. Tracy, L. Downe, and J. Holberton, "How safe is intermittent positive pressure ventilation in preterm babies ventilated from delivery to newborn intensive care unit?" Archives of Disease in Childhood-Fetal and Neonatal Edition, vol. 89, no. 1, pp. F84F87, 2004.

[36] O. Dammann, E. N. Allred, L. J. van Marter, C. E. L. Dammann, and A. Leviton, "Bronchopulmonary dysplasia is not associated with ultrasound-defined cerebral white matter damage in preterm newborns," Pediatric Research, vol. 55, no. 2, pp. 319325, 2004.

[37] C. D. Lilley, M. Stewart, and C. J. Morley, "Respiratory function monitoring during neonatal emergency transport," Archives of Disease in Childhood_Fetal and Neonatal Edition, vol. 90, no. 1, pp. F82-F83, 2005.

[38] C. P. F. O’Donnell, C. O. F. Kamlin, P. G. Davis, and C. J. Morley, "Neonatal resuscitation 1: a model to measure inspired and expired tidal volumes and assess leakage at the face mask," Archives of Disease in Childhood-Fetal and Neonatal Edition, vol. 90, no. 5, pp. F388-F391, 2005.

[39] G. M. Schmölzer, D. A. Poulton, J. A. Dawson, C. O. F. Kamlin, C. J. Morley, and P. G. Davis, "Assessment of flow waves and colorimetric $\mathrm{CO} 2$ detector for endotracheal tube placement during neonatal resuscitation," Resuscitation, vol. 82, no. 3, pp. 307-312, 2011.

[40] G. M. Schmölzer, S. B. Hooper, K. J. Crossley, B. J. Allison, C. J. Morley, and P. G. Davis, "Assessment of gas flow waves for endotracheal tube placement in an ovine model of neonatal resuscitation," Resuscitation, vol. 81, no. 6, pp. 737-741, 2010.

[41] G. Schmölzer, R. Bhatia, P. G. Davis, and D. Tingay, "A comparison of different bedside techniques to determine endotracheal tube position in a neonatal piglet model," Pediatric Pulmonology, vol. 48, no. 2, pp. 138-145, 2013.

[42] G. M. Schmölzer, J. A. Dawson, C. O. F. Kamlin et al., "Airway obstruction and gas leak during mask ventilation of preterm infants in the delivery room," Archives of Disease in ChildhoodFetal and Neonatal Edition, vol. 96, pp. F254-F257, 2011.

[43] A. B. te Pas, C. Wong, C. O. F. Kamlin, J. A. Dawson, C. J. Morley, and P. G. Davis, "Breathing patterns in preterm and term infants immediately after birth," Pediatric Research, vol. 65, no. 3, pp. 352-356, 2009.

[44] A. B. te Pas, P. G. Davis, C. O. F. Kamlin, J. Dawson, C. P. F. O'Donnell, and C. J. Morley, "Spontaneous breathing patterns of very preterm infants treated with continuous positive airway pressure at birth," Pediatric Research, vol. 64, no. 3, pp. 281-285, 2008.

[45] A. B. te Pas, C. O. F. Kamlin, J. A. Dawson et al., "Ventilation and spontaneous breathing at birth of infants with congenital diaphragmatic hernia," The Journal of Pediatrics, vol. 154, no. 3, pp. 369-373, 2009.

[46] N. N. Finer, W. Rich, C. Wang, and T. Leone, "Airway obstruction during mask ventilation of very low birth weight infants during neonatal resuscitation," Pediatrics, vol. 123, no. 3, pp. 865-869, 2009.

[47] K. I. Wheeler, P. G. Davis, C. O. F. Kamlin, and C. J. Morley, "Assist control volume guarantee ventilation during surfactant administration," Archives of Disease in Childhood-Fetal and Neonatal Edition, vol. 94, no. 5, pp. F336-F338, 2009.

[48] G. M. Schmölzer, C. O. F. Kamlin, J. A. Dawson et al., "Tidal volume delivery during surfactant administration in the 
delivery room," Intensive Care Medicine, vol. 37, no. 11, pp. 18331839, 2011.

[49] A. B. te Pas, P. G. Davis, S. B. Hooper, and C. J. Morley, "From liquid to air: breathing after birth," The Journal of Pediatrics, vol. 152, no. 5, pp. 607-611, 2008.

[50] B. Lachmann, G. Grossmann, R. Nilsson, and B. Robertson, "Lung mechanics during spontaneous ventilation in premature and fullterm rabbit neonates," Respiration Physiology, vol. 38, no. 3, pp. 283-302, 1979.

[51] G. Lista, F. Castoldi, P. Fontana et al., "Lung inflammation in preterm infants with respiratory distress syndrome: effects of ventilation with different tidal volumes," Pediatric Pulmonology, vol. 41, no. 4, pp. 357-363, 2006.

[52] N. H. Hillman, T. J. M. Moss, S. G. Kallapur et al., "Brief, large tidal volume ventilation initiates lung injury and a systemic response in fetal sheep," American Journal of Respiratory and Critical Care Medicine, vol. 176, no. 6, pp. 575-581, 2007.

[53] D. Dreyfuss and G. Saumon, "Barotrauma is volutrauma, but which volume is the one responsible?" Intensive Care Medicine, vol. 18, no. 3, pp. 139-141, 1992.

[54] D. Dreyfuss and G. Saumon, "Role of tidal volume, FRC, and end-inspiratory volume in the development of pulmonary edema following mechanical ventilation," American Review of Respiratory Disease, vol. 148, no. 5, pp. 1194-1203, 1993.

[55] D. Dreyfuss, G. Basset, P. Soler, and G. Saumon, "Intermittent positive-pressure hyperventilation with high inflation pressures produces pulmonary microvascular injury in rats," American Review of Respiratory Disease, vol. 132, no. 4, pp. 880-884, 1985.

[56] M. South and C. J. Morley, "Monitoring spontaneous respiration in the ventilated neonate," Archives of Disease in Childhood, vol. 61, pp. 291-294, 1986.

[57] V. K. Bhutani, "Clinical applications of pulmonary function and graphics," Seminars in Neonatology, vol. 7, no. 5, pp. 391-399, 2002.

[58] S. Hosono, I. Inami, H. Fujita, M. Minato, S. Takahashi, and H. Mugishima, "A role of end-tidal CO2 monitoring for assessment of tracheal intubations in very low birth weight infants during neonatal resuscitation at birth," Journal of Perinatal Medicine, vol. 37, no. 1, pp. 79-84, 2009.

[59] C. O. F. Kamlin, C. P. F. O’Donnell, P. G. Davis, and C. J. Morley, "Colorimetric end-tidal carbon dioxide detectors in the delivery room: strengths and limitations. A case report," The Journal of Pediatrics, vol. 147, no. 4, pp. 547-548, 2005.

[60] L. L. D. Aliwalas, L. Noble, K. Nesbitt, S. Fallah, V. Shah, and P. S. Shah, "Agreement of carbon dioxide levels measured by arterial, transcutaneous and end tidal methods in preterm infants $\leq 28$ weeks gestation," Journal of Perinatology, vol. 25, no. 1, pp. 2629, 2005.

[61] A. Kugelman, D. Zeiger-Aginsky, D. Bader, I. Shoris, and A. Riskin, "A novel method of distal end-tidal CO2 capnography in intubated infants: comparison with Arterial CO2 and with proximal mainstream end-tidal CO2," Pediatrics, vol. 122, no. 6, pp. e1219-e1224, 2008.

[62] J. D. Tobias, "Transcutaneous carbon dioxide monitoring in infants and children," Paediatric Anaesthesia, vol. 19, no. 5, pp. 434-444, 2009.

[63] E. J. Molloy, "Are carbon dioxide detectors useful in neonates?" Archives of Disease in Childhood-Fetal and Neonatal Edition, vol. 91, pp. F295-F298, 2006.

[64] M. Vento, P. Y. Cheung, and M. Aguar, "The first golden minutes of the extremely-low-gestational-age neonate: a gentle approach," Neonatology, vol. 95, no. 4, pp. 286-298, 2009.
[65] E. D. Bowman and R. N. D. Roy, "Control of temperature during newborn transport: an old problem with new difficulties," Journal of Paediatrics and Child Health, vol. 33, no. 5, pp. 398401, 1997.

[66] E. D. Johnston, J. C. Becher, A. P. Mitchell, and B. J. Stenson, "Provision of servo-controlled cooling during neonatal transport," Archives of Disease in Childhood-Fetal and Neonatal Edition, 2011.

[67] S. E. Jacobs, C. J. Morley, T. E. Inder et al., "Wholebody hypothermia for term and near-term newborns with hypoxic-ischemic encephalopathy: a randomized controlled trial," Archives of Pediatrics and Adolescent Medicine, vol. 165, no. 8, pp. 692-700, 2011.

[68] F. Khurshid, K.-S. Lee, P. J. McNamara et al., "Lessons learned during implementation of therapeutic hypothermia for neonatal hypoxic ischemic encephalopathy in a regional transport program in Ontario," Paediatrics \& Child Health, vol. 16, pp. 153156, 2011.

[69] K. Fairchild, D. Sokora, J. Scott, and S. Zanelli, “Therapeutic hypothermia on neonatal transport: 4-year experience in a single NICU," Journal of Perinatology, vol. 30, no. 5, pp. 324-329, 2010.

[70] G. S. Kendall, A. Kapetanakis, N. Ratnavel, D. Azzopardi, and N. J. Robertson, "Passive cooling for initiation of therapeutic hypothermia in neonatal encephalopathy," Archives of Disease in Childhood-Fetal and Neonatal Edition, vol. 95, no. 6, pp. F408F412, 2010.

[71] S. K. Lee, J. A. Zupancic, J. Sale et al., "Cost-effectiveness and choice of infant transport systems," Medical Care, vol. 40, pp. 705-716, 2002.

[72] M. C. Hermansen, S. Hasan, J. Hoppin, and M. D. Cunningham, "A validation of a scoring system to evaluate the condition of transported very-low-birthweight neonates," American Journal of Perinatology, vol. 5, no. 1, pp. 74-78, 1988.

[73] A. Ferrara and Y. Atakent, "Neonatal stabilization score. A quantitative method of auditing medical care in transported newborns weighing less than 1,000 g at birth," Medical Care, vol. 24, no. 2, pp. 179-187, 1986.

[74] S. K. Lee, J. A. F. Zupancic, M. Pendray et al., “Transport risk index of physiologic stability: a practical system for assessing infant transport care," The Journal of Pediatrics, vol. 139, no. 2, pp. 220-226, 2001.

[75] S. J. Broughton, A. Berry, S. Jacobe, P. Cheeseman, W. O. Tarnow-Mordi, and A. Greenough, "The mortality index for neonatal transportation score: a new mortality prediction model for retrieved neonates," Pediatrics, vol. 114, no. 4, pp. e424-e428, 2004.

[76] D. K. Richardson, J. D. Corcoran, G. J. Escobar, and S. K. Lee, "SNAP-II and SNAPPE-II: simplified newborn illness severity and mortality risk scores," The Journal of Pediatrics, vol. 138, no. 1, pp. 92-100, 2001.

[77] P. Lucas da Silva, V. Euzébio de Aguiar, and M. Reis, "Assessing outcome in interhospital infant transport: the transport risk index of physiologic stability score at admission," American Journal of Perinatology, vol. 29, no. 7, pp. 509-514, 2012. 


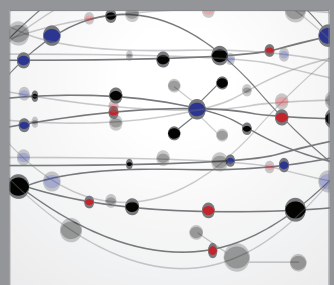

The Scientific World Journal
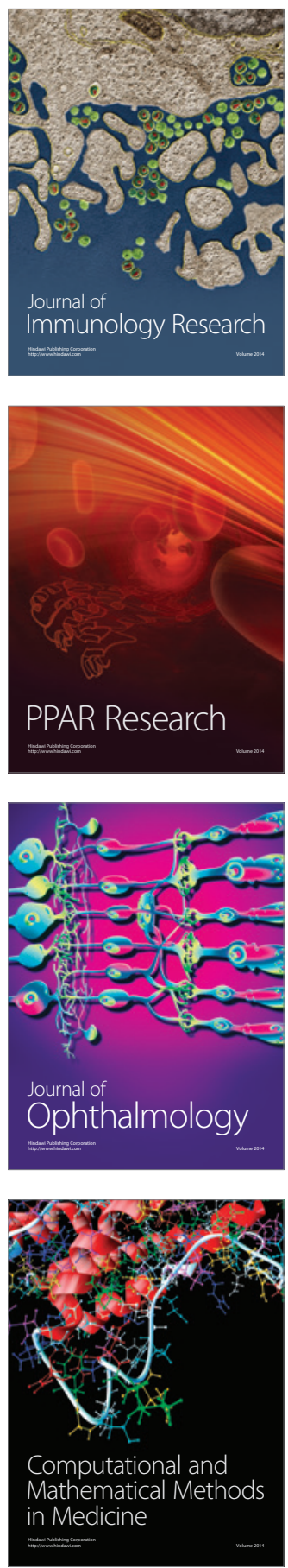

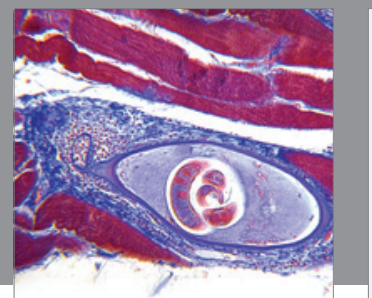

Gastroenterology

Research and Practice
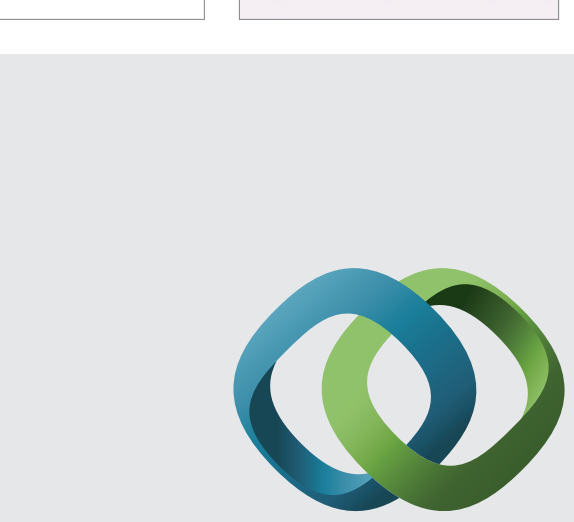

\section{Hindawi}

Submit your manuscripts at

http://www.hindawi.com
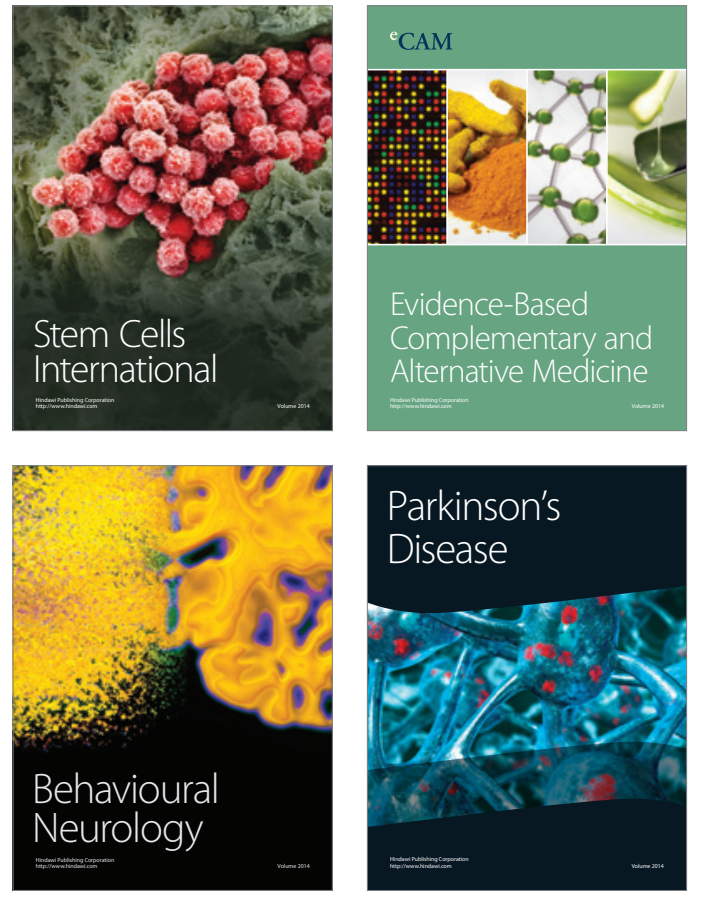


Disease Markers
